\title{
Agreement of Dental Students in the Detection of Normal Landmarks When Comparing Digital Lateral Cephalograms and Three-Dimensional Cone Beam Computed Tomography Images
}

\author{
Zahra Dalili Kajan, ${ }^{1,}$ Navid Karimi Nasab, ${ }^{2}$ Jalil Khademi, ${ }^{2}$ Faegheh Gholinia, ${ }^{2}$ Zeinab Taheri, ${ }^{3}$ and \\ Mona Hajighadimi ${ }^{4}$ \\ ${ }^{1}$ Oral and Maxillofacial Radiology Department, Dental School, Guilan University of Medical Sciences, Rasht, IR Iran \\ ${ }^{2}$ Orthodontics Department, Dental School, Guilan University of Medical Sciences, Rasht, IR Iran \\ ${ }^{3}$ Dentist, Dental School, Guilan University of Medical Sciences, Rasht, IR Iran \\ ${ }^{4}$ Dentist, Private Clinic, Rasht, IR Iran \\ "Corresponding author: Zahra Dalili Kajan, Oral and Maxillofacial Radiology Department, Dental School, Guilan University of Medical Sciences, Rasht, IR Iran. Tel: \\ +98-1313263622; +98-9111343432, Fax: +98-1313263621, E-mail: zahradalili@yahoo.com
}

Received 2016 January 03; Accepted 2016 January 26.

\begin{abstract}
Background: Proper defining of normal landmarks in lateral cephalograms is important for establishing proper orthodontic treatment plan.

Objectives: To evaluate the agreement of dental students to identify normal landmarks (NLs) in digital lateral cephalograms and cone beam computed tomography (CBCT) images.

Patients and Methods: In this study, lateral cephalograms and CBCT images of 11 orthodontic patients were selected. Three fourthyear dental students were asked to identify 19 NLs after calibrating digital lateral cephalograms and 3D CBCT images. Then, the distances of each landmark from the superior and anterior edges of the images were measured for each observer.

Results: The observers' errors fell within a range of -1.03 to 2.74 in two-dimensional cephalometry and a range of -0.88 to 2.31 in 3D CBCT, showing a $95 \%$ limit of agreement. According to the intraclass correlation coefficient (ICC) comparison made by our student observers, only $5 \%$ of interobserver assessment in CBCT and $20 \%$ in lateral cephalometry showed poor reliability. These same observers showed more agreement when identifying NLs on soft tissue as compared to hard tissue structures and also in detecting NLs located in the midsagittal region rather than on lateral sides in both modalities. Their differences in agreement in detecting midsagittal NLs rather than on lateral sides were statistically significant $(P=0.0001)$.

Conclusions: The training of cephalometric tracing in orthodontic course based on 3D skull models and imaginary methods was deemed successful in increasing the ability of dental students to determine the precise location of NLs, even on CBCT images.
\end{abstract}

Keywords: Anatomic Landmark, Cephalometry, Cone Beam Computed Tomography

\section{Background}

Since introducing the first standardized cephalograms, cephalometric analysis has become a necessity in designing orthodontic treatment. Several factors that influence the detection and tracing of normal landmarks on lateral cephalograms are image quality, accuracy and reproducibility. In cephalometric analysis, errors may occur that are caused by the geometry of the X-ray beam, overlapping anatomical structures, the different magnification of bilateral structures and patient head position (1-3). Projectional magnification and distortion could lead to variations in orthodontic and surgical treatment planning (4). Many anatomical landmarks used in cephalometric analysis are located in the midsagittal plane and are not prone to the errors of structural superimposition, but other paramedial structures become distorted because of their locations in different depths (1).

New technological advances in craniofacial imaging such as CBCT improve the ability of identifying anatomical landmarks by providing the facility of reconstructing three-dimensional (3D) images. It seems that CBCT technology allows us to overcome the inherent errors of twodimensional (2D) cephalograms and to further improve the identification of cephalometric landmarks (5). As a result, by using СBCT images, the accuracy and reliability of observers in identifying normal landmarks increase (68). The most important advantages of using CBCT lateral cephalograms are the ability to reposition or to realign the head orientation digitally when the patient's head position is not correct and to generate separate images of both left and right sides which are used to properly assess facial asymmetry (5). Primary reconstruction of the right and 
left sides in CBCT prevents projectional magnification that is seen in conventional cephalograms (9).

Replacement of conventional radiographs with 3D images may be an unavoidable or predictable trend especially in complicated skeletal deformities. In order for the orthodontic community to accept this inevitable transition from 2D to 3D analysis, achieving harmony of CBCTderived analysis with the analysis of the existing database on lateral cephalograms is necessary $(8,10)$. Various studies have been performed to evaluate normal landmarks on CBCT-derived cephalograms $(11,12)$. In addition, the precision and accuracy of measurements made via CBCT images have been studied by several investigators (11, 13-15). It has been reported that measurements on CBCT-derived cephalograms did not clinically differ from those on conventional cephalograms in vivo or in vitro $(11,13)$.

Reliability of 3D analysis of anatomical landmarks and the feasibility of correctly identifying anatomical features in their respective sites has been studied, but not fully accepted yet $(16,17)$.

Inconsistency in properly defining landmarks is one of the major sources of error made when attempting to obtain reliable and accurate cephalometric measurements. In addition to imaging quality, many other variables potentially influence landmark identification errors, including the location and characteristics of individual landmarks, the experience of the observer and the information available regarding the patient's personal/treatment history (i.e. age, sex, metallic restorations in the mouth and facial asymmetry). However, the many variables that potentially affect landmark identification errors in CBCT cephalograms are not completely known yet (12).

Cephalometric landmark tracing-based teaching on 2 D cephalometric radiographs is important in orthodontic courses. The concerns about transitioning from using 2D images to 3D scans can be reduced by knowing the degree to which 2D training on landmark identification may be generalized to achieving accurate landmark identification in 3D images as most oral specialists, especially orthodontists, are more familiar with identifying normal landmarks in $2 \mathrm{D}$ images. As a result, it is thought not to be that easy to adapt dental practitioners to using 3D imaginary methods.

\section{Objectives}

This study was designed to investigate the effect of routine orthodontic training course during dental education on the degree of agreement that exists among dental students when making an assessment of normal landmarks in $3 \mathrm{D}$ views of CBCT images. We want to confirm that we only focused on the effects of $2 \mathrm{D}$ orthodontic training on perception of 3D views of CBCT modality.

\section{Patients and Methods}

In this descriptive-analytical study, we compared 11 randomly selected digital lateral cephalograms with their corresponding $\mathrm{CBCT}$ images obtained from a private dental imaging clinic. The selected orthodontic patients did not have syndromal or craniofacial diseases. High quality lateral cephalometric images were available for these patients who also needed CBCT for various reasons which included diagnosing impacted teeth or performing other dental examinations. Before conducting this research, we obtained the approval of the ethics committee of the Guilan University of Medical Sciences research foundation (ethics approval number 1390) in Rasht, Iran to ensure our compliance with the recommendations of the declaration of Helsinki and Tokyo for humans including all amendments and revisions.

Digital lateral cephalograms were captured by storage phosphor plate cassettes using a Planmeca Ec Proline machine (Planmeca, Helsinki, Finland). These images were then scanned and digitized using a CR system scanner (Konica Minolta holdings, Inc., Tokyo, Japan). After ensuring the quality of the images and making the desired adjustments to show density and contrast, they were transferred to a PACS system (PACSPLUS, Orange County, CA) as digital imaging and communications in medicine (DICOM) data and then exported to an electronic folder of cephalometric images as jpg.formatted images. Exposure settings were different for various patients. All cephalometric images were prepared by stabilizing the patient's head in a natural position using ear rods.

CBCT images were acquired with a New Tom VG device (QR Srl Company,Verona, Italy) by selecting a 9-inch field of view (FOV) in a head position similar to that in which the patient had been stabilized using cephalometric units but without employing extracranial references (i.e. a ruler and the chain). After first taking the required volumetric images, study images having a 1-mm axial slice thickness were then generated. Lateral 3D images taken in volume model style and in bone model color to show hard and soft tissue aspects were reconstructed using NNT Viewer software, Version 2.21. The Camera Shot tool available in this NNT Viewer software was employed to take a photo from 3D images. These photos were then stored in jpg.format in an electronic 3D image folder.

All digital cephalograms were calibrated in sizes ranging from 160 to $210 \mathrm{~mm}$ and had a 290 pixels/inch resolution. These images were then exported to Photoshop software (middle eastern version) for pinpoint detection of normal landmarks (Figure 1). Three fourth-year dental students, who had been trained only in cephalometric analysis in an orthodontic course with the same in- 
structor that had more than ten years of teaching experience, were asked to locate 19 normal landmarks. Training in cephalometric analysis had been based on attending lectures and practicing on printed radiographs. The contents of these lectures on cephalometric analysis were based on the demonstration of normal landmarks on skull models and in conventional radiographs. Before detecting specified landmarks, their definitions, as depicted in Table 1 , were given to each student observer. Terms are defined by three experienced $\left(10^{+}\right.$years each) orthodontists as co-investigators. For bilateral landmarks, these same observers identified the ones that had more clarity. Then the student observers identified the same normal landmarks on 3D images, including lateral views of 3D-reconstructed hard (Figure 2A) and soft tissue images (Figure 2B) in the same manner as they had done for the previously viewed 2D images.

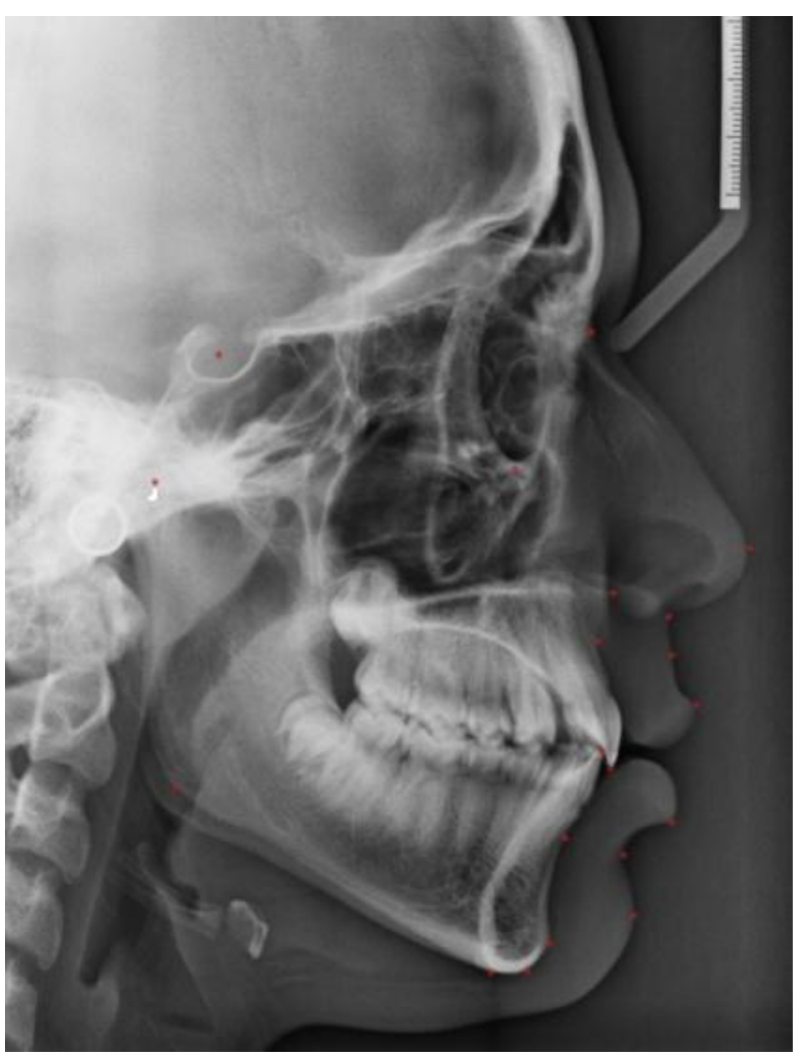

Figure 1. Pinpoint Detection of Normal Landmarks on Lateral Cephalograms Using Photoshop Software

Afterwards, 2D and 3D images traced by each observer were subsequently transferred to SCANORA software (Sordex, Helsinki, Finland) and the distances of each normal landmark detected by each observer to the anterior and the upper edges were measured by a co-investigator of this
Figure 2. 3D CBCT Images

A

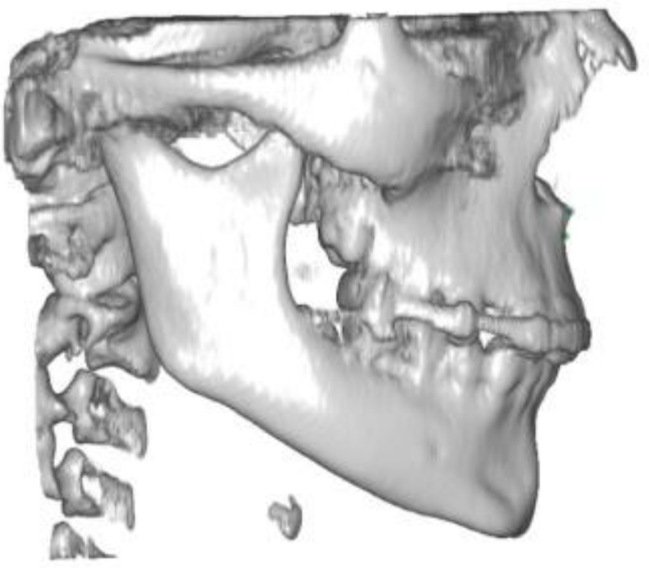

B

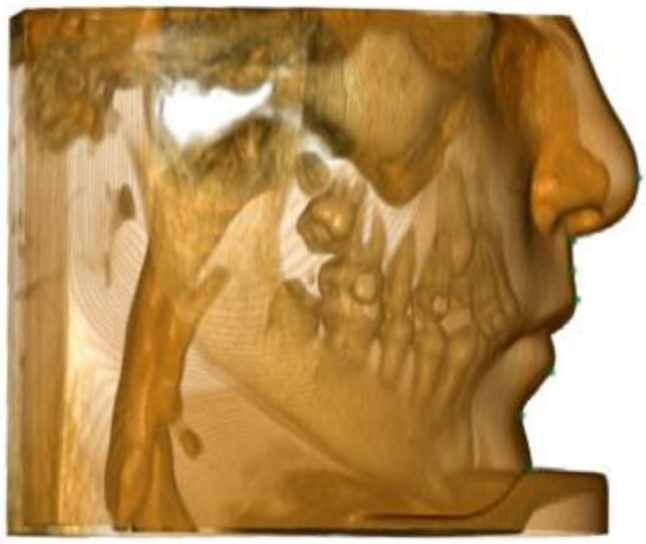

A, Lateral view with hard tissue reconstruction; B, Lateral view with soft tissue reconstruction.

study as horizontal (X-) and vertical (Y-) measurements of normal landmarks (Figures 3 and $4 \mathrm{~A}$ and $\mathrm{B}$ ).

\subsection{Statistical Analysis}

Data were entered into SPSS Version 19 software (SPSS, Chicago, IL) and both X-and Y- measurements of each normal landmark as calculated for our 11 subjects in both imaging modalities were compared for our three observers. To determine the best estimate of the true value for each anatomical landmark, we used the average of the three student observers' estimates made of each landmark 
Table 1. Definition of Hard and Soft Tissue Landmarks

\begin{tabular}{|c|c|}
\hline Landmark & Definition \\
\hline A-point (A) & Deepest point of the maxillary base between the anterior nasal spine and the alveolar crest \\
\hline Anterior Nasal Spine (ANS) & Tip of the anterior nasal spine \\
\hline B-Point (B) & Deepest point in the concavity of the anterior border of the symphysis \\
\hline Condylion (Con) & The most posterior superior point of the right condyle \\
\hline Gonion (Go) & The most convex point where the posterior and inferior curves of the ascending ramus meet each other \\
\hline Maxillary Incisor Edge (MIE) & Tip of the right maxillary central incisor \\
\hline Menton (Me) & Most inferior point of the symphysis \\
\hline Nasion $(\mathbf{N})$ & Most anterior superior point at the intersection of the nasal bone and the nasofrontal suture in the midsagittal plane \\
\hline Orbitale (Or) & Most inferior point of outer border of the orbital cavity \\
\hline Pogonion (Pog) & Most anterior point on the midsagittal symphysis \\
\hline Porion (Po) & Most superior point of the right external auditory canal \\
\hline Soft Tissue A-Point (A') & Most concave point between the subnasale and the anterior point of upper lip \\
\hline Soft Tissue B-Point (B') & Most concave point between the lower lip and the soft tissue chin \\
\hline Soft Tissue Pogonion (Pog') & Most anterior point on the anterior curve of the soft tissue chin \\
\hline Soft Tissue Nasal Tip (NT) & Most anterior point on the curve of the nose \\
\hline Subnasale (Sn) & Point where the nose connects to the center of the upper lip \\
\hline Labrale Inferius (LI) & Most anterior point on the curve of the lower lip \\
\hline Labrale Superius (LS) & Most anterior point on the curve of the upper lip \\
\hline
\end{tabular}

as described by Baumrind and Frantz (18) as the gold standard.

To evaluate reliability, we used X- and Y-values, calculated by using the 3D imaging method to allow for reasonable comparison of these distances shown when using the 2D imaging modality. Note Z-values (i.e. depth measurements) were not used to study reliability.

To determine the respective mean errors, we used the average of the absolute value of the difference of our three student observers distance estimation from the best estimation point of each normal landmark location in the $\mathrm{X}$ and Y-directions for both imaging modalities.

Intraclass correlation coefficients (ICCs) were used to determine the agreement levels observed among our student observers. An ICC of less than $85 \%$ was considered to be the low level of significant difference. The Bland-Altman test was used to assess the agreement levels between our 2D and 3D methods and to establish the interobserver reliability coefficient (IRC). A P value $\leq 0.05$ was considered as statistically significant.

\section{Results}

In this study, 19 normal anatomical landmarks were evaluated using digital lateral 2D cephalograms and 3D CBCT images of 11 orthodontic patients. Three fourth-year dental students were asked to identify these normal landmarks after calibrating images in both imaging modalities.

Table 2 reveals the best estimation of each anatomical landmark location studied and depicts standard errors made by our observers in each modality when identifying these sites in both $\mathrm{X}$ - and Y-directions.

The comparison between mean errors made by our student observers when viewing images in both 2D and 3D imaging modalities is shown in Table 3. According to the Table 3 ANS in the $\mathrm{X}$-direction $(\mathrm{P}=0.001), \mathrm{N}$ in the $\mathrm{Y}$ direction $(P=0.014)$, Or in the $Y$-direction $(P<0.001)$ and Pog' in the Y-direction $(P=0.01)$ show statistically significant differences between the two imaging methods. However, in 3D CBCT, the errors or variations of our student observers in the detection of anatomical landmarks were lower than those found in $2 \mathrm{D}$ cephalometry. It was the reverse for the detection of $\operatorname{Con}(\mathrm{P}=0.033)$ and $\operatorname{MIE}(\mathrm{P}=0.021)$ in the X-direction. A mean error greater than $1 \mathrm{~mm}$ in the 


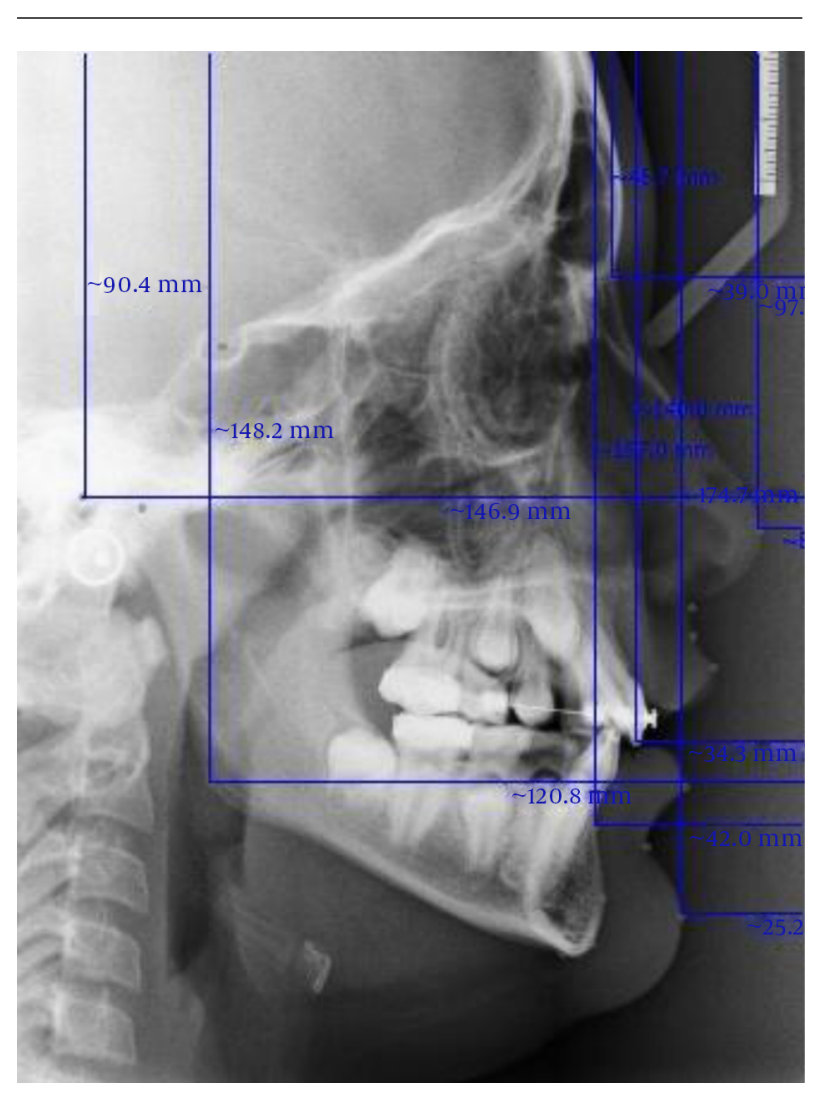

Figure 3. Measuring distances of each normal landmark to the anterior and upper borders of the image by using Photoshop software in 2D modality.

detection of normal landmarks was reported more often in 3D CBCT images than in 2D cephalograms.

The ICC test was used for evaluation of our student observers' variations in their levels of agreement when detecting of normal landmarks in both X-and Y-directions (Table 4). Variations between these three observers were reported 15\% more frequently in the detection of Pog' in the Y-direction and in the recognition of ANS and Or in the Xdirection in the 2D modality, but they were not statistically significant. The ICC in the detection of A in the Y-direction in both 2D and 3D imaging modalities was not significant, although in recognizing other normal landmarks, the ICC of the observers being greater than 0.85 and having a $\mathrm{P}$ value of $\leq 0.5$ was ideal.

Table 5 shows the mean errors made by our student observers in the localization of anatomical landmarks on soft and hard tissues in both 2D and 3D modalities.

The mean student observer errors in the detection of normal landmarks that were located on lateral sides were greater in the midsagittal plane in both modalities. Moreover, they were statistically significant $(\mathrm{P}=0.0001)$.

The interobserver reliability coefficient (IRC) of ob- servers in each modality as determined by Bland-Altman analysis is shown in Table 6 . The limit of observer agreement in $2 \mathrm{D}$ imaging modality was greater than in $3 \mathrm{D}$ modality, but it was not statistically significant.

\section{Discussion}

However, diagnostic errors are the main source of cephalometric tracing errors and could be related to technical and/or individual judgment errors. In cephalometric analysis, the observer's reliability in detecting normal landmarks has a close correlation with both the educational level and practical experience of observers. Various studies $(19,20)$ have confirmed that interobserver differences might have the most significant effects on the reliability of accurately detecting anatomical landmarks, a conclusion that concurs with our results.

Chien et al. have shown that 2D lateral cephalograms in comparison with 3D images had greater than 1-mm errors in X-and/or Y-directions in detecting the following landmarks: ANS, A, Con, basion, Or, Po and midramus. The Go in the Y-direction had greater error in 3D images compared to 2D ones (7). In our study, mean student observer errors occurred three times more frequently in the detection of ANS in the X-direction as well as the recognition of $\mathrm{N}$ and Or landmarks in the Y-direction when comparing 2D with 3D imaging modalities. Mean observer errors in the detection of MIE and Con in the X-direction occurred 1.5 times more frequently in the $3 \mathrm{D}$ rather than the $2 \mathrm{D}$ modality. In our study, similar to other studies $(7,18,21)$ the error in localizing ANS and Or landmarks in 2D lateral cephalograms as compared to 3D CBCT was greater and, moreover, statistically significant. However, it was not similar in the detection of Con and Po.

In the Lagravere et al. study (20), inter- and intraexaminer reliability in the detection of most landmarks in lateral cephalograms was reported at a greater than 0.9 level except for Po, basion and Con in the Y-direction. In our study, when detecting A in the Y-direction in the 3D modality and in recognizing A and Pog' in the Y-direction as well as ANS and Or in the X-direction in the 2D modality, the ICC of our three student observers was weak in relation to the expected ICC of 0.85; thus, it was not statistically significant. With regard to detecting other normal landmarks, the ICC was reported as good and it was statistically significant. The ICC in the detection of A in 3D CBCT comparing with 2D cephalograms was greater. Considering the importance of the detection of A when using cephalometric analysis, the variability in observer recognition of this anatomical point in conventional cephalograms contributes to the problems in making correct landmark identification therein. Detecting Pog' in soft tissue in 

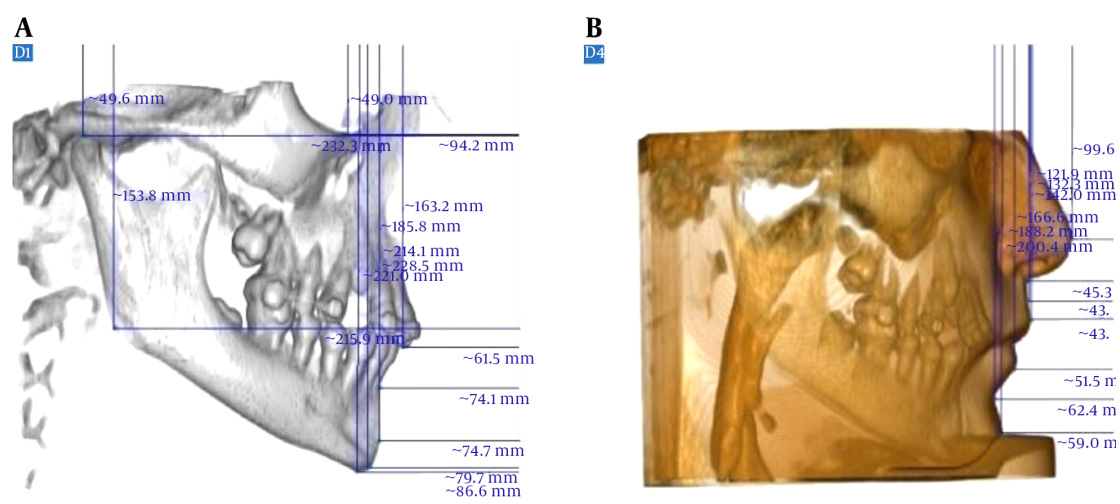

A, Hard tissue reconstruction; B, Soft tissue reconstruction.

Table 5. Comparison Between Overall Mean Errors Made by Student Observers in Hard and Soft Tissues in Each Imaging Modality ${ }^{\mathrm{a}}$

\begin{tabular}{|c|c|c|c|c|c|}
\hline Direction & Landmark Status & $\mathbf{N}$ & Mean & Standard Deviation & PValue \\
\hline \multicolumn{6}{|c|}{ 2D Modality } \\
\hline \multirow[t]{3}{*}{$\mathbf{x}$} & & & & & 0.000 \\
\hline & Hard tissue & 143 & 0.9691 & 1.08877 & \\
\hline & Soft tissue & 77 & 0.3071 & 0.20465 & \\
\hline \multirow[t]{3}{*}{$\mathbf{Y}$} & & & & & 0.039 \\
\hline & Hard tissue & 143 & 1.0699 & 0.97662 & \\
\hline & Soft tissue & 77 & 0.7983 & 0.81716 & \\
\hline \multicolumn{6}{|c|}{ 3D Modality } \\
\hline \multirow[t]{3}{*}{$\mathbf{X}$} & & & & & 0.031 \\
\hline & Hard tissue & 143 & 1.0233 & 3.69711 & \\
\hline & Soft tissue & 77 & 0.3469 & 0.26081 & \\
\hline \multirow[t]{3}{*}{$\mathbf{Y}$} & & & & & 0.014 \\
\hline & Hard tissue & 143 & 0.9354 & 1.03248 & \\
\hline & Soft tissue & 77 & 0.6309 & 0.43509 & \\
\hline
\end{tabular}

${ }^{\mathrm{a}} \mathrm{X}$, Horizontal direction; $\mathrm{Y}$, Vertical direction; $\mathrm{P} \leq 0.05$.

Table 6. The Agreement Levels of Student Observers in the Detection of Normal Landmarks When Viewing 2D or 3D Images

\begin{tabular}{lcccc}
\hline Modality & Bias $\pm \mathbf{S D}, \mathbf{~ m m}^{\mathbf{a}}$ & Range of bias, $\mathbf{~ m m}$ & 95\% Limit of Agreement, $\mathbf{m m}$ & Interobserver Reliability Coefficient (IRC) \\
\hline 2D & $0.8561 \pm 0.9419$ & $0-7.91$ & $-1.03-2.74$ & 1.71 \\
3D & $0.7151 \pm 0.7959$ & $0-4.87$ & $-.88-2.31$ & 1.43 \\
\hline
\end{tabular}

${ }^{\mathrm{a}} \mathrm{SD}$, Standard deviation; Bland-Altman test.

the 2D modality was more difficult than in 3D due to having less soft tissue contrast. The difficulty in correctly detecting the ANS landmark could be due to the superimposition of the shadow of the nasal ala on it. The superimposi- tion that one side makes on the other side of the face could be the reason for the more difficult detection of Or in $2 \mathrm{D}$ modality.

Various studies have revealed that the measurements 
on CBCT-generated cephalograms are more accurate than those calculated in conventional cephalograms $(22,23)$. Kumar et al. (11) has compared conventional cephalograms and CBCT-generated cephalograms on dry skulls and from human samples and have shown that there were no statistically significant differences. In our study, the mean error in the detection of anatomical landmarks in lateral cephalograms was greater than in CBCT. Additional investigations $(13,24)$ have revealed that the method of imaging is not an important variable in the detection of cephalometric landmarks. However, in this study, our student observers showed greater agreement in the detection of normal landmarks and proved that the imaging modality used, i.e. 3D as compared to 2D is important.

de Oliveira et al. (25) have evaluated the reliability of observers in 3D-landmark identification using CBCT. They showed that $3 \%$ of IRCs were $<0.45$. The ICC was reported as $>0.9$ for $66 \%$ of interobserver assessments. A poor indication of reliability was shown in the Y- and Zcoordinates as indicated by an ICC $<0.45$ for two cases (6.66\%) in the Y-coordinate and for one case (3.3\%) in the Zcoordinate, thereby affecting only three interobserver assessments (3.3\%). Two bilateral landmarks, i.e. the right and left ramus in the Y-coordinate and in the right and left Con in the Z-coordinate, showed low ICC scores (25). In our study, no ICC $<0.45$ was reported. In only one normal landmark (A in the Y-direction) in 3D and four landmarks in the 2D modality (A and Pog' in the Y-direction as well as ANS and Or in the X-direction), the ICC was reported as < 0.85 . The interobserver ICC in the detection of other normal landmarks was $>0.85$ and, thus, considered to be excellent. Overall, only $5 \%$ of interobserver assessments in 3D CBCT and $20 \%$ of interobserver assessments in using 2D cephalograms were $<0.85$ and, therefore, classified as poor.

Perez Couceiro and de Vasconcellos Vilella suggested 3D images are more reliable for the identification of Po, Or, $\mathrm{A}, \mathrm{B}$ and $\mathrm{N}$ landmarks as all of these are difficult to detect in 2D cephalograms. Similarly, the lower mandibular border was identified in 3D modality more easily (26).

In our study ANS, N, Or and Pog' in the Y-direction were detected with less error in 3D than in 2D modality.

Couceiro and Vilella study (26) also assert that the values of the measurements taken from 3D images showed less discrepancy and greater reliability when identifying some cephalometric landmarks. This finding is compatible with Nakajima et al. (27) and our study. Chang et al. (12) have revealed that landmark identification errors on the CBCT-derived cephalograms were greater for N, Or, and ANS and less for Pog, Gn, Me, and basion landmarks. In our study, landmark identification errors in digital lateral cephalograms were also greater for ANS, N, Or and Pog' than those made on 3D CBCT images.

In our study, mean errors in the detection of normal landmarks located located on lateral sides were more frequently made in identifying midsagittal landmarks in both modalities. This finding is compatible with Kumar et al. (13) and Gribel et al. (23) Greater lateral landmark identification errors e.g Or could be related those of a physical character because many observers had experienced difficulty in detecting landmarks on blurred images of superimposed bilateral structures (16). Ludlow et al. (28) have reported that the reliability of 3D landmark identification on CBCT volumetric images was more precise for bilateral landmarks such as Go and Or as compared with conventional 2D cephalograms.

Overall, our mean student observer errors in locating of soft tissue landmarks were less frequently made in 3D than in 2D modality. Even the agreement of these observers in locating soft tissue landmarks was greater than detecting hard tissue ones. This is related to the character of soft tissue landmarks located in the midsagittal plane that show less superimposition and have proper contrast resolution.

The teaching program of our orthodontics course on the topic of lateral cephalogram tracing was based on having students identify cephalometric landmarks on radiographs after they had imagined those same points on the skull while attending lectures that had been accompanied by PowerPoint slide presentations. Then the students had to find and trace the landmarks on the printed radiographs themselves and review them with their professors or they were asked to detect new landmarks using an interactive model. This method of teaching seems to be effective in enhancing the ability of dental students to locate anatomical landmarks on CBCT without their having to undergo special training.

\subsection{Conclusion}

Mean observer errors in detecting anatomical landmarks in 2D lateral cephalograms were greater than in 3D CBCT modality, but they were not statistically significant. In both methods, our student observers in the detection of the midsagittal plane and soft tissue landmarks also showed greater agreement. Therefore, the training of 2D cephalometric analysis based on 3D imagination for dental students could be helpful in 3D CBCT analysis.

\section{Acknowledgments}

We are grateful to Julie Monti Safari for her assistance in editing the text herein. In addition, we would like to 
thank Pejman Kiani for his providing technical and software support during preparation of required samples. Finally, we would like to acknowledge Ehsan Kazemnezhad Leili, PhD (department of biostatistics, school of medicine, Guilan University of Medical Sciences, Rasht, Iran) for his assistance in analyzing the statistical data. We also wish to confirm that there are no known conflicts of interest associated with this publication and there has been no significant financial support for this work that could have influenced its outcome.

\section{References}

1. Bergersen EO. Enlargement and distortion in cephalometric radiography: compensation tables for linear measurements. Angle Orthod. 1980;50(3):230-44. doi: 10.1043/00033219(1980)050<0230:EADICR>2.0.CO;2. [PubMed: 6931505].

2. Major PW, Johnson DE, Hesse KL, Glover KE. Landmark identification error in posterior anterior cephalometrics. Angle Orthod. 1994;64(6):447-54. doi: 10.1043/00033219(1994)064<0447:LIEIPA>2.0.CO;2. [PubMed: 7864466].

3. Chen YJ, Chen SK, Chang HF, Chen KC. Comparison of landmark identification in traditional versus computer-aided digital cephalometry. Angle Orthod. 2000;70(5):387-92. doi: 10.1043/00033219(2000)070<0387:COLIIT>2.0.CO;2. [PubMed: 11036999].

4. Ahlqvist J, Eliasson S, Welander U. The effect of projection errors on cephalometric length measurements. Eur J Orthod. 1986;8(3):141-8. [PubMed: 3464437].

5. Mah JK, Huang JC, Choo H. Practical applications of cone-beam computed tomography in orthodontics. J Am Dent Assoc. 2010;141 Suppl 3:7S-13S. [PubMed: 20884934].

6. Mah J, Hatcher D. Three-dimensional craniofacial imaging. Am J Orthod Dentofacial Orthop. 2004;126(3):308-9. doi: 10.1016/S0889540604005621. [PubMed: 15356493].

7. Chien PC, Parks ET, Eraso F, Hartsfield JK, Roberts WE, Ofner S. Comparison of reliability in anatomical landmark identification using two-dimensional digital cephalometrics and three-dimensional cone beam computed tomography in vivo. Dentomaxillofac Radiol. 2009;38(5):262-73. doi: 10.1259/dmfr/81889955. [PubMed: 19474253].

8. Cattaneo PM, Bloch CB, Calmar D, Hjortshoj M, Melsen B. Comparison between conventional and cone-beam computed tomography-generated cephalograms. Am J Orthod Dentofacial Orthop. 2008;134(6):798-802. doi: 10.1016/j.ajodo.2008.07.008. [PubMed: 19061807].

9. Baumgaertel S, Palomo JM, Palomo L, Hans MG. Reliability and accuracy of cone-beam computed tomography dental measurements. Am J Orthod Dentofacial Orthop. 2009;136(1):19-25. doi: 10.1016/j.ajodo.2007.09.016. [PubMed: 19577143] discussion 25-8.

10. Graber TM, Vanarsdall RL, Vig KWL. Orthodontics: current principles and techniques. 4 ed. St Louis: Elsevier Mosby; 2005. pp. 71-100.

11. Kumar V, Ludlow JB, Mol A, Cevidanes L. Comparison of conventional and cone beam CT synthesized cephalograms. Dentomaxillofac Radiol. 2007;36(5):263-9. doi: 10.1259/dmfr/98032356. [PubMed: 17586852].

12. Chang ZC, Hu FC, Lai E, Yao CC, Chen MH, Chen YJ. Landmark identification errors on cone-beam computed tomography-derived cephalograms and conventional digital cephalograms. Am J Orthod Dentofacial Orthop. 2011;140(6):e289-97. doi: 10.1016/j.ajodo.2011.06.024. [PubMed: 22133963].

13. Kumar V, Ludlow J, Soares Cevidanes LH, Mol A. In vivo comparison of conventional and cone beam CT synthesized cephalograms. Angle Orthod. 2008;78(5):873-9. doi: 10.2319/082907-399.1. [PubMed: 18298214].

14. Lamichane M, Anderson NK, Rigali PH, Seldin EB, Will LA. Accuracy of reconstructed images from cone-beam computed tomogra- phy scans. Am J Orthod Dentofacial Orthop. 2009;136(2):156 e1-6. doi: 10.1016/j.ajodo.2009.04.006. [PubMed: 19651340] discussion 156-7.

15. van Vlijmen OJ, Berge SJ, Swennen GR, Bronkhorst EM, Katsaros C, Kuijpers-Jagtman AM. Comparison of cephalometric radiographs obtained from cone-beam computed tomography scans and conventional radiographs. J Oral Maxillofac Surg. 2009;67(1):92-7. doi: 10.1016/j.joms.2008.04.025. [PubMed: 19070753].

16. Lou L, Lagravere MO, Compton S, Major PW, Flores-Mir C. Accuracy of measurements and reliability of landmark identification with computed tomography (CT) techniques in the maxillofacial area: a systematic review. Oral Surg Oral Med Oral Pathol Oral Radiol Endod. 2007;104(3):402-11. doi: 10.1016/j.tripleo.2006.07.015. [PubMed: 17709072].

17. Lagravere MO, Major PW. Proposed reference point for 3-dimensional cephalometric analysis with cone-beam computerized tomography. Am J Orthod Dentofacial Orthop. 2005;128(5):657-60. doi: 10.1016/j.ajodo.2005.07.003. [PubMed: 16286215].

18. Baumrind S, Frantz RC. The reliability of head film measurements. 1. Landmark identification. Am J Orthod. 1971;60(2):111-27. [PubMed: 5283996].

19. Chen YJ, Chen SK, Huang HW, Yao CC, Chang HF. Reliability of landmark identification in cephalometric radiography acquired by a storage phosphor imaging system. Dentomaxillofac Radiol. 2004;33(5):301-6. doi: 10.1259/dmfr/85147715. [PubMed: 15585806].

20. Lagravere MO, Low C, Flores-Mir C, Chung R, Carey JP, Heo G, et al. Intraexaminer and interexaminer reliabilities of landmark identification on digitized lateral cephalograms and formatted 3-dimensional cone-beam computerized tomography images. Am J Orthod Dentofacial Orthop. 2010;137(5):598-604. doi: 10.1016/j.ajodo.2008.07.018. [PubMed: 20451778].

21. McClure SR, Sadowsky PL, Ferreira A, Jacobson A, editors. Reliability of digital versus conventional cephalometric radiology: a comparative evaluation of landmark identification error. Semin Orthod. 2005; Elsevier; pp. 98-110.

22. Moshiri M, Scarfe WC, Hilgers ML, Scheetz JP, Silveira AM, Farman AG. Accuracy of linear measurements from imaging plate and lateral cephalometric images derived from cone-beam computed tomography. Am J Orthod Dentofacial Orthop. 2007;132(4):550-60. doi: 10.1016/j.ajodo.2006.09.046. [PubMed:17920510].

23. Gribel BF, Gribel MN, Frazao DC, McNamara Jr JA, Manzi FR. Accuracy and reliability of craniometric measurements on lateral cephalometry and 3D measurements on CBCT scans. Angle Orthod. 2011;81(1):2635. doi: 10.2319/032210-166.1. [PubMed: 20936951].

24. Cattaneo PM, Melsen B. The use of cone-beam computed tomography in an orthodontic department in between research and daily clinic. World J Orthod. 2008;9(3):269-82. [PubMed:18834009].

25. de Oliveira AE, Cevidanes LH, Phillips C, Motta A, Burke B, Tyndall D. Observer reliability of three-dimensional cephalometric landmark identification on cone-beam computerized tomography. Oral Surg Oral Med Oral Pathol Oral Radiol Endod. 2009;107(2):256-65. doi: 10.1016/j.tripleo.2008.05.039. [PubMed:18718796].

26. Couceiro CP, Vilella ODV. 2D/3D cone-beam CT images or conventional radiography:Which is more reliable?. Dental Press J Orthod. 2010;15(5):40-1.

27. Nakajima A, Sameshima GT, Arai Y, Homme Y, Shimizu N, Dougherty $\mathrm{Sr} \mathrm{H}$. Two- and three-dimensional orthodontic imaging using limited cone beam-computed tomography. Angle Orthod. 2005;75(6):895903. doi: 10.1043/0003-3219(2005)75[895:TATOIU]2.0.CO;2. [PubMed: 16448229].

28. Ludlow JB, Gubler M, Cevidanes L, Mol A. Precision of cephalometric landmark identification: cone-beam computed tomography vs conventional cephalometric views. Am J Orthod Dentofacial Orthop. 2009;136(3):312 e1-10. doi: 10.1016/j.ajodo.2008.12.018. [PubMed: 19732656] discussion 312-3. 
Table 2. The Best Estimation of and Standard Errors Made in Identifying Each Landmark Location When Using 2D and 3D Imaging Modalities ${ }^{\mathrm{a}}$

\begin{tabular}{|c|c|c|c|c|}
\hline \multirow[t]{2}{*}{ Directions of Modality } & \multirow[t]{2}{*}{ Estimate } & \multirow[t]{2}{*}{ Standard Error } & \multicolumn{2}{|c|}{ 95\% Confidence Interval } \\
\hline & & & \multirow[t]{2}{*}{ Lower Boundary } & \multirow[t]{2}{*}{ Upper Boundary } \\
\hline & & Landmark A & & \\
\hline \multicolumn{5}{|l|}{ 2D } \\
\hline $\mathrm{x}$ & 40.96 & 1.66 & 37.13 & 44.79 \\
\hline $\mathrm{Y}$ & 127.45 & 2.52 & 121.63 & 133.26 \\
\hline \multicolumn{5}{|l|}{ 3D } \\
\hline $\mathrm{x}$ & 58.07 & 4.57 & 47.54 & 68.6 \\
\hline $\mathrm{Y}$ & 124.93 & 3.26 & 117.42 & 132.45 \\
\hline \multicolumn{5}{|c|}{ Landmark ANS } \\
\hline \multicolumn{5}{|l|}{ 2D } \\
\hline $\mathrm{x}$ & 37.37 & 1.84 & 33.11 & 41.62 \\
\hline Y & 119.18 & 1.6 & 115.48 & 122.87 \\
\hline \multicolumn{5}{|l|}{ 3D } \\
\hline $\mathrm{x}$ & 54.92 & 5.92 & 41.26 & 68.58 \\
\hline $\mathrm{Y}$ & 114.69 & 2.71 & 108.44 & 120.94 \\
\hline \multicolumn{5}{|c|}{ Landmark B } \\
\hline \multicolumn{5}{|l|}{ 2D } \\
\hline $\mathrm{x}$ & 49.87 & 2.34 & 44.47 & 55.27 \\
\hline $\mathrm{Y}$ & 168.01 & 3.12 & 160.83 & 175.2 \\
\hline \multicolumn{5}{|l|}{ 3D } \\
\hline $\mathrm{x}$ & 70.69 & 5.12 & 58.88 & 82.51 \\
\hline $\mathrm{Y}$ & 188.31 & 4.4 & 178.17 & 198.46 \\
\hline \multicolumn{5}{|c|}{ Landmark Con } \\
\hline \multicolumn{5}{|l|}{ 2D } \\
\hline $\mathrm{x}$ & 134.74 & 2.16 & 129.76 & 139.71 \\
\hline $\mathrm{Y}$ & 95.53 & 3.44 & 87.59 & 103.46 \\
\hline \multicolumn{5}{|l|}{ 3D } \\
\hline $\mathrm{x}$ & 218.54 & 6.83 & 202.78 & 234.29 \\
\hline Y & 70.86 & 8.34 & 51.63 & 90.08 \\
\hline \multicolumn{5}{|c|}{ Landmark Gn } \\
\hline \multicolumn{5}{|l|}{ 2D } \\
\hline $\mathrm{x}$ & 51.93 & 2.29 & 46.66 & 57.2 \\
\hline $\mathrm{Y}$ & 190.9 & 1.73 & 186.92 & 194.89 \\
\hline \multicolumn{5}{|l|}{ 3D } \\
\hline $\mathrm{x}$ & 73.99 & 5.12 & 62.18 & 85.81 \\
\hline Y & 224.15 & 4.39 & 214.03 & 234.26 \\
\hline & & Landmark Go & & \\
\hline 2D & & & & \\
\hline $\mathrm{x}$ & 129.02 & 2.72 & 122.74 & 135.29 \\
\hline $\mathrm{Y}$ & 154.35 & 2.44 & 148.73 & 159.98 \\
\hline 3D & & & & \\
\hline $\mathrm{x}$ & 206.72 & 5.84 & 193.24 & 220.19 \\
\hline $\mathrm{Y}$ & 161.86 & 4.49 & 151.5 & 172.22 \\
\hline & & Landmark MIE & & \\
\hline 2D & & & & \\
\hline $\mathrm{x}$ & 38.6 & 2.67 & 32.44 & 44.76 \\
\hline $\mathrm{Y}$ & 151.71 & 2.83 & 145.19 & 158.24 \\
\hline 3D & & & & \\
\hline $\mathrm{x}$ & 53.76 & 4.15 & 44.19 & 63.33 \\
\hline $\mathrm{Y}$ & 164.36 & 2.84 & 157.81 & 170.92 \\
\hline & & Landmark Me & & \\
\hline 2D & & & & \\
\hline $\mathrm{x}$ & 59.02 & 2.48 & 53.3 & 64.74 \\
\hline
\end{tabular}




\begin{tabular}{|c|c|c|c|c|c|}
\hline & Y & 192.14 & 1.51 & 188.66 & 195.62 \\
\hline \multicolumn{6}{|c|}{ 3D } \\
\hline & $\mathrm{x}$ & 83.4 & 4.57 & 72.87 & 93.94 \\
\hline & Y & 226.56 & 4.71 & 215.69 & 237.43 \\
\hline \multicolumn{6}{|c|}{ Landmark N } \\
\hline \multicolumn{6}{|c|}{ 2D } \\
\hline & $\mathrm{x}$ & 42.32 & 2.15 & 37.36 & 47.28 \\
\hline \multicolumn{6}{|c|}{ 3D } \\
\hline & $\mathrm{x}$ & 56.29 & 9.1 & 35.31 & 77.28 \\
\hline & Y & 82.13 & 12.72 & 52.79 & 111.46 \\
\hline \multicolumn{6}{|c|}{ Landmark Or } \\
\hline \multicolumn{6}{|c|}{ 2D } \\
\hline & $\mathrm{x}$ & 61.72 & 1.8 & 57.56 & 65.88 \\
\hline \multicolumn{6}{|l|}{ 3D } \\
\hline & $\mathrm{x}$ & 86.39 & 5.33 & 74.11 & 98.67 \\
\hline & Y & 60.2 & 4.4 & 50.05 & 70.35 \\
\hline \multicolumn{6}{|c|}{ Landmark Pog } \\
\hline \multicolumn{6}{|c|}{ 2D } \\
\hline & $\mathrm{x}$ & 61.22 & 2.14 & 56.28 & 66.17 \\
\hline & Y & 173.28 & 10.45 & 149.18 & 197.39 \\
\hline \multicolumn{6}{|l|}{ 3D } \\
\hline & $\mathrm{x}$ & 70.08 & 4.57 & 59.54 & 80.62 \\
\hline & Y & 214.65 & 5.04 & 203.03 & 226.26 \\
\hline \multicolumn{6}{|c|}{ Landmark Po } \\
\hline \multicolumn{6}{|c|}{ 2D } \\
\hline & $\mathrm{x}$ & 148.49 & 1.83 & 144.28 & 152.71 \\
\hline & Y & 91.35 & 2.96 & 84.53 & 98.16 \\
\hline & Y & 86.46 & 13.42 & 55.52 & 117.4 \\
\hline \multicolumn{6}{|c|}{ Landmark A' } \\
\hline \multicolumn{6}{|c|}{ 2D } \\
\hline & $x$ & 25.42 & 1.55 & 21.84 & 29 \\
\hline & Y & 131.92 & 2.82 & 125.42 & 138.42 \\
\hline \multicolumn{6}{|l|}{ 3D } \\
\hline & $\mathrm{x}$ & 33.33 & 5.61 & 20.39 & 46.27 \\
\hline & Y & 137.67 & 2.53 & 131.83 & 143.5 \\
\hline \multicolumn{6}{|c|}{ Landmark B' } \\
\hline \multicolumn{6}{|c|}{ 2D } \\
\hline & $\mathrm{x}$ & 37.22 & 2.37 & 31.76 & 42.68 \\
\hline & Y & 168.92 & 2.06 & 164.16 & 173.68 \\
\hline 3D & & & & & \\
\hline & $\mathrm{x}$ & 52.92 & 2.21 & 47.82 & 58.02 \\
\hline & Y & 189.58 & 2.67 & 183.42 & 195.73 \\
\hline & & & Landmar & & \\
\hline 2D & & & & & \\
\hline & $\mathrm{x}$ & 33.78 & 2.81 & 27.3 & 40.27 \\
\hline & Y & 183.07 & 2.07 & 178.3 & 187.84 \\
\hline 3D & & & & & \\
\hline & $\mathrm{x}$ & 50.75 & 5.45 & 38.17 & 63.32 \\
\hline & Y & 205.89 & 2.43 & 200.3 & 211.49 \\
\hline & & & Landma & & \\
\hline 2D & & & & & \\
\hline & $\mathrm{x}$ & 7.13 & 1.16 & 4.47 & 9.8 \\
\hline & Y & 110.47 & 2.73 & 104.17 & 116.77 \\
\hline
\end{tabular}




\begin{tabular}{|c|c|c|c|c|}
\hline \multicolumn{5}{|l|}{ 3D } \\
\hline $\mathrm{x}$ & 13.09 & 2.85 & 6.53 & 19.65 \\
\hline Y & 150.13 & 16.8 & 111.38 & 188.88 \\
\hline \multicolumn{5}{|c|}{ Landmark Sn } \\
\hline \multicolumn{5}{|l|}{ 2D } \\
\hline $\mathrm{x}$ & 23.52 & 1.1 & 20.99 & 26.06 \\
\hline Y & 124.51 & 3.45 & 116.55 & 132.48 \\
\hline \multicolumn{5}{|l|}{ 3D } \\
\hline$x$ & 29.63 & 5.74 & 16.4 & 42.86 \\
\hline Y & 125.13 & 2.81 & 118.66 & 131.61 \\
\hline \multicolumn{5}{|c|}{ Landmark LI } \\
\hline \multicolumn{5}{|l|}{ 2D } \\
\hline $\mathrm{x}$ & 27.69 & 1.94 & 23.22 & 32.16 \\
\hline $\mathrm{Y}$ & 161.63 & 2.91 & 154.92 & 168.33 \\
\hline \multicolumn{5}{|l|}{ 3D } \\
\hline $\mathrm{x}$ & 39.38 & 5.61 & 26.45 & 52.31 \\
\hline Y & 179.56 & 2.77 & 173.16 & 185.95 \\
\hline \multicolumn{5}{|c|}{ Landmark LS } \\
\hline \multicolumn{5}{|l|}{ 2D } \\
\hline $\mathrm{x}$ & 22.22 & 1.54 & 18.66 & 25.78 \\
\hline Y & 138.9 & 3.12 & 131.7 & 146.1 \\
\hline \multicolumn{5}{|l|}{ 3D } \\
\hline $\mathrm{x}$ & 29.72 & 4.9 & 18.42 & 41.01 \\
\hline Y & 147.27 & 2.12 & 142.38 & 152.16 \\
\hline
\end{tabular}

${ }^{\mathrm{a}} \mathrm{X}$, Horizontal direction; $\mathrm{Y}$, Vertical direction. 
Table 3. A Comparison Between Mean Errors Made by Our Three Student Observers in the Detection of Landmarks Observed in 2D and 3D Images (Number $=11)$ For Each Direction $^{\mathrm{a}}$

\begin{tabular}{|c|c|c|c|}
\hline Directions of Modality & Mean Error & Standard Deviation & PValue \\
\hline \multicolumn{4}{|c|}{ Landmark A } \\
\hline \multicolumn{4}{|l|}{$\mathrm{x}$} \\
\hline $2 \mathrm{D}$ & 0.6869 & 0.83364 & 0.293 \\
\hline $3 \mathrm{D}$ & 0.404 & 0.24299 & \\
\hline \multicolumn{4}{|l|}{$\mathbf{Y}$} \\
\hline $2 \mathrm{D}$ & 1.6525 & 1.70148 & 0.476 \\
\hline $3 \mathrm{D}$ & 2.1818 & 1.71408 & \\
\hline \multicolumn{4}{|c|}{ Landmark ANS } \\
\hline \multicolumn{4}{|l|}{$\mathrm{x}$} \\
\hline $2 \mathrm{D}$ & 2.8566 & 2.05686 & 0.001 \\
\hline $3 \mathrm{D}$ & 0.3091 & 0.1941 & \\
\hline \multicolumn{4}{|l|}{$\mathbf{Y}$} \\
\hline $2 \mathrm{D}$ & 0.8081 & 0.54896 & 0.021 \\
\hline 3D & 0.3576 & 0.22867 & \\
\hline \multicolumn{4}{|c|}{ Landmark B } \\
\hline \multicolumn{4}{|l|}{$\mathrm{x}$} \\
\hline $2 \mathrm{D}$ & 0.3939 & 0.39228 & 0.55 \\
\hline 3D & 0.4909 & 0.35576 & \\
\hline \multicolumn{4}{|l|}{$\mathbf{Y}$} \\
\hline $2 \mathrm{D}$ & 1.4343 & 1.14177 & 0.979 \\
\hline $3 \mathrm{D}$ & 1.4465 & 1.0403 & \\
\hline \multicolumn{4}{|c|}{ Landmark Con } \\
\hline \multicolumn{4}{|l|}{$\mathrm{x}$} \\
\hline $2 \mathrm{D}$ & 1.6 & 0.63191 & 0.033 \\
\hline $3 \mathrm{D}$ & 2.2808 & 0.75531 & \\
\hline \multicolumn{4}{|l|}{$\mathbf{Y}$} \\
\hline $2 \mathrm{D}$ & 1.5434 & 1.11126 & 0.798 \\
\hline 3D & 1.6424 & 0.61169 & \\
\hline \multicolumn{4}{|c|}{ Landmark Gn } \\
\hline \multicolumn{4}{|l|}{$\mathbf{x}$} \\
\hline $2 \mathrm{D}$ & 0.6889 & 0.41276 & 0.268 \\
\hline 3D & 0.9737 & 0.71993 & \\
\hline \multicolumn{4}{|l|}{$\mathbf{Y}$} \\
\hline $2 \mathrm{D}$ & 0.7354 & 0.27079 & 0.502 \\
\hline $3 \mathrm{D}$ & 0.8505 & 0.4891 & \\
\hline \multicolumn{4}{|c|}{ Landmark Go } \\
\hline \multicolumn{4}{|l|}{$\mathrm{x}$} \\
\hline $2 \mathrm{D}$ & 1.0727 & 0.52504 & 0.139 \\
\hline $3 \mathrm{D}$ & 0.7111 & 0.574 & \\
\hline \multicolumn{4}{|l|}{$\mathbf{Y}$} \\
\hline $2 \mathrm{D}$ & 0.8404 & 0.52265 & 0.42 \\
\hline 3D & 1.0303 & 0.55948 & \\
\hline \multicolumn{4}{|c|}{ Landmark MIE } \\
\hline \multicolumn{4}{|l|}{$\mathrm{x}$} \\
\hline $2 \mathrm{D}$ & 0.1879 & 0.12186 & 0.021 \\
\hline 3D & 0.3838 & 0.22816 & \\
\hline \multicolumn{4}{|l|}{$\mathbf{Y}$} \\
\hline $2 \mathrm{D}$ & 0.3434 & 0.1628 & 0.051 \\
\hline $3 \mathrm{D}$ & 0.202 & 0.15602 & \\
\hline & Lan & & \\
\hline $\mathrm{x}$ & & & \\
\hline $2 \mathrm{D}$ & 1.2101 & 0.75806 & 0.46 \\
\hline
\end{tabular}




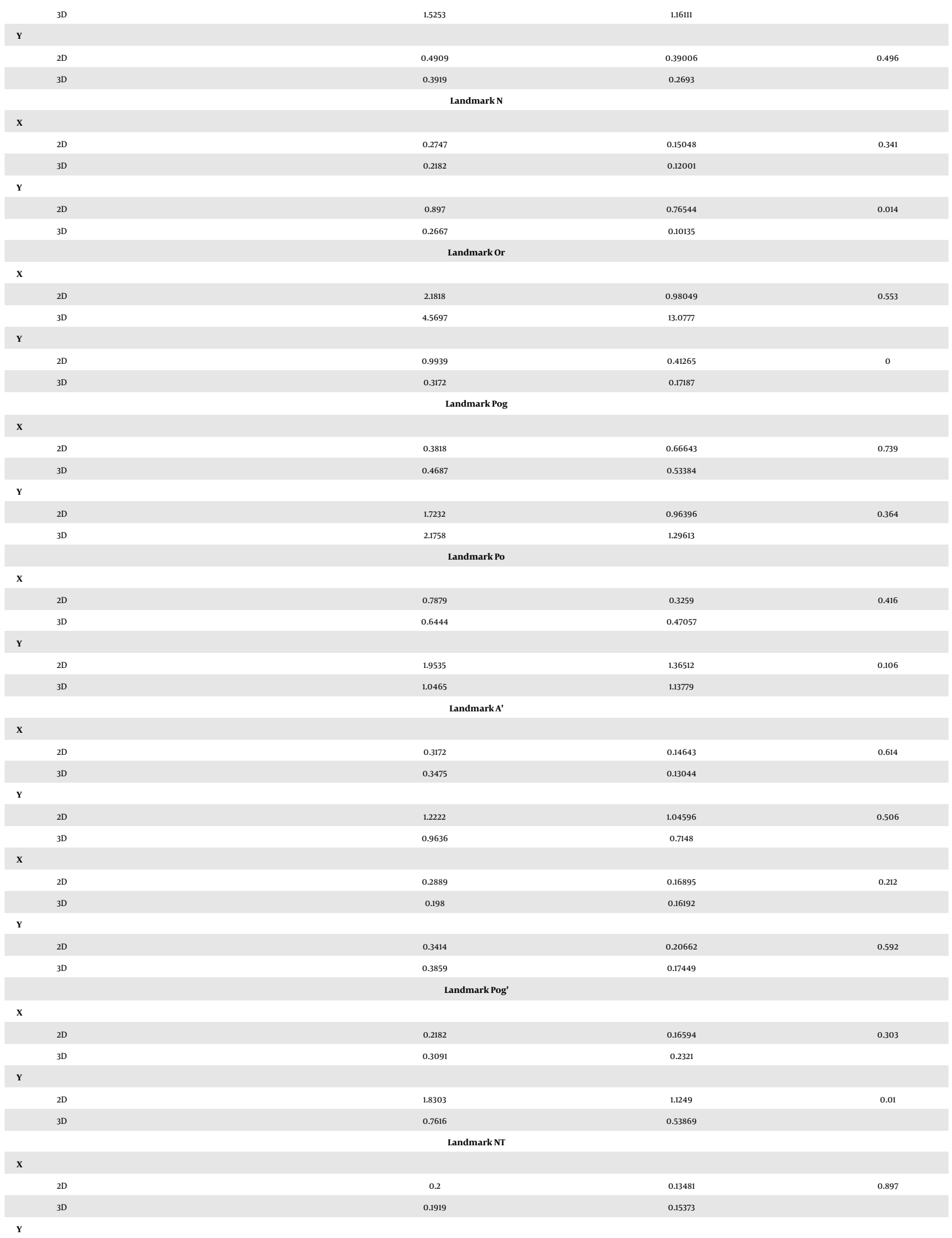




\begin{tabular}{|c|c|c|c|}
\hline $2 \mathrm{D}$ & 0.7919 & 0.77059 & 0.303 \\
\hline $3 \mathrm{D}$ & 0.5313 & 0.27207 & \\
\hline \multicolumn{4}{|c|}{ Landmark Sn } \\
\hline \multicolumn{4}{|l|}{$\mathrm{x}$} \\
\hline $2 \mathrm{D}$ & 0.4 & 0.24845 & 0.265 \\
\hline $3 \mathrm{D}$ & 0.5535 & 0.36804 & \\
\hline \multicolumn{4}{|l|}{ Y } \\
\hline $2 \mathrm{D}$ & 0.4646 & 0.1892 & 0.107 \\
\hline 3D & 0.6303 & 0.26523 & \\
\hline \multicolumn{4}{|c|}{ Landmark LI } \\
\hline \multicolumn{4}{|l|}{$\mathrm{x}$} \\
\hline $2 \mathrm{D}$ & 0.3939 & 0.29882 & 0.19 \\
\hline $3 \mathrm{D}$ & 0.5616 & 0.28058 & \\
\hline \multicolumn{4}{|l|}{$\mathbf{Y}$} \\
\hline $2 \mathrm{D}$ & 0.3939 & 0.18542 & 0.057 \\
\hline $3 \mathrm{D}$ & 0.6182 & 0.31737 & \\
\hline \multicolumn{4}{|c|}{ Landmark LS } \\
\hline \multicolumn{4}{|l|}{$\mathrm{x}$} \\
\hline $2 \mathrm{D}$ & 0.3313 & 0.17707 & 0.377 \\
\hline 3D & 0.2667 & 0.15776 & \\
\hline \multicolumn{4}{|l|}{$\mathbf{Y}$} \\
\hline $2 \mathrm{D}$ & 0.5434 & 0.19022 & 0.885 \\
\hline $3 \mathrm{D}$ & 0.5253 & 0.36342 & \\
\hline
\end{tabular}


Table 4. Interobserver Reliability Intraclass Correlation Coefficients in the Detection of Anatomical Landmarks When Using 2D and 3D Imaging Methods ${ }^{\mathrm{a}}$

\begin{tabular}{|c|c|c|c|c|}
\hline \multirow[t]{2}{*}{ Modalities of Direction } & \multirow[t]{3}{*}{ ICC } & \multicolumn{2}{|c|}{ 95\% Confidence Interval } & \multirow[t]{3}{*}{ PValue } \\
\hline & & Lower Boundary & \multirow[t]{2}{*}{ Upper Boundary } & \\
\hline \multicolumn{2}{|c|}{ Landmark A } & & & \\
\hline $\mathrm{x}$ & 0.956 & 0.878 & 0.987 & 0.009 \\
\hline Y & 0.897 & 0.714 & 0.97 & 0.227 \\
\hline \multicolumn{5}{|l|}{ 3D } \\
\hline $\mathrm{Y}$ & 0.921 & 0.781 & 0.977 & 0.106 \\
\hline \multicolumn{5}{|c|}{ Landmark ANS } \\
\hline \multicolumn{5}{|l|}{ 2D } \\
\hline $\mathrm{x}$ & 0.752 & 0.312 & 0.927 & 0.792 \\
\hline $\mathrm{Y}$ & 0.988 & 0.967 & 0.997 & 0 \\
\hline \multicolumn{5}{|l|}{ 3D } \\
\hline Y & 0.996 & 0.989 & 0.999 & 0 \\
\hline \multicolumn{5}{|c|}{ Landmark B } \\
\hline \multicolumn{5}{|l|}{ 2D } \\
\hline $\mathrm{x}$ & 0.991 & 0.975 & 0.997 & 0 \\
\hline $\mathrm{Y}$ & 0.951 & 0.865 & 0.986 & 0.015 \\
\hline \multicolumn{5}{|l|}{ 3D } \\
\hline $\mathrm{x}$ & 0.998 & 0.995 & 0.999 & 0 \\
\hline $\mathrm{Y}$ & 0.984 & 0.957 & 0.995 & 0 \\
\hline \multicolumn{5}{|c|}{ Landmark Con } \\
\hline \multicolumn{5}{|l|}{ 2D } \\
\hline $\mathrm{x}$ & 0.976 & 0.934 & 0.993 & 0 \\
\hline $\mathrm{Y}$ & 0.962 & 0.894 & 0.989 & 0.004 \\
\hline \multicolumn{5}{|l|}{ 3D } \\
\hline $\mathrm{x}$ & 0.996 & 0.989 & 0.999 & 0 \\
\hline \multicolumn{5}{|l|}{ 2D } \\
\hline $\mathrm{x}$ & 0.988 & 0.966 & 0.996 & 0 \\
\hline $\mathrm{Y}$ & 0.99 & 0.972 & 0.997 & 0 \\
\hline 3D & & & & \\
\hline $\mathrm{x}$ & 0.994 & 0.984 & 0.998 & 0 \\
\hline $\mathrm{Y}$ & 0.995 & 0.987 & 0.999 & 0 \\
\hline & & dmark Go & & \\
\hline 2D & & & & \\
\hline$x$ & 0.977 & 0.935 & 0.993 & 0 \\
\hline $\mathrm{Y}$ & 0.985 & 0.957 & 0.995 & 0 \\
\hline 3D & & & & \\
\hline $\mathrm{x}$ & 0.998 & 0.994 & 0.999 & 0 \\
\hline $\mathrm{Y}$ & 0.995 & 0.985 & 0.998 & 0 \\
\hline & & Imark MIE & & \\
\hline 2D & & & & \\
\hline$x$ & 0.999 & 0.997 & 1 & 0 \\
\hline $\mathrm{Y}$ & 0.998 & 0.994 & 0.999 & 0 \\
\hline 3D & & & & \\
\hline $\mathrm{x}$ & 0.999 & 0.998 & 1 & 0 \\
\hline $\mathrm{Y}$ & 0.999 & 0.998 & 1 & 0 \\
\hline & & dmark Me & & \\
\hline 2D & & & & \\
\hline $\mathrm{x}$ & 0.946 & 0.849 & 0.984 & 0.025 \\
\hline
\end{tabular}




\begin{tabular}{|c|c|c|c|c|c|}
\hline & Y & 0.989 & 0.969 & 0.997 & 0 \\
\hline \multicolumn{6}{|c|}{ 3D } \\
\hline & $\mathrm{x}$ & 0.983 & 0.952 & 0.995 & 0 \\
\hline & Y & 0.998 & 0.996 & 1 & 0 \\
\hline \multicolumn{6}{|c|}{ Landmark N } \\
\hline \multicolumn{6}{|l|}{ 2D } \\
\hline & $\mathrm{x}$ & 0.996 & 0.989 & 0.999 & 0 \\
\hline \multicolumn{6}{|l|}{ 3D } \\
\hline & $\mathrm{x}$ & 1 & 1 & 1 & 0 \\
\hline & Y & 1 & 1 & 1 & 0 \\
\hline \multicolumn{6}{|c|}{ Landmark Or } \\
\hline \multicolumn{6}{|c|}{ 2D } \\
\hline & $\mathrm{x}$ & 0.914 & 0.761 & 0.975 & 0.14 \\
\hline \multicolumn{6}{|l|}{ 3D } \\
\hline & $\mathrm{x}$ & 0.994 & 0.983 & 0.998 & 0 \\
\hline & Y & 0.999 & 0.997 & 1 & 0 \\
\hline \multicolumn{6}{|c|}{ Landmark Pog } \\
\hline \multicolumn{6}{|c|}{ 2D } \\
\hline & $\mathrm{x}$ & 1 & 0.999 & 1 & 0 \\
\hline & Y & 0.999 & 0.996 & 1 & 0 \\
\hline \multicolumn{6}{|l|}{ 3D } \\
\hline & $\mathrm{x}$ & 0.998 & 0.994 & 0.999 & 0 \\
\hline & Y & 0.979 & 0.943 & 0.994 & 0 \\
\hline \multicolumn{6}{|c|}{ Landmark Po } \\
\hline \multicolumn{6}{|c|}{ 2D } \\
\hline & $\mathrm{x}$ & 0.969 & 0.915 & 0.991 & 0.001 \\
\hline & Y & 0.959 & 0.887 & 0.988 & 0.006 \\
\hline \multicolumn{6}{|l|}{ 3D } \\
\hline & $\mathrm{Y}$ & 0.999 & 0.997 & 1 & 0 \\
\hline \multicolumn{6}{|c|}{ Landmark A' } \\
\hline \multicolumn{6}{|l|}{ 2D } \\
\hline & $\mathrm{x}$ & 0.991 & 0.974 & 0.997 & 0 \\
\hline & Y & 0.974 & 0.927 & 0.992 & 0 \\
\hline \multicolumn{6}{|l|}{ 3D } \\
\hline & $\mathrm{x}$ & 0.999 & 0.998 & 1 & 0 \\
\hline & Y & 0.974 & 0.929 & 0.993 & 0 \\
\hline \multicolumn{6}{|c|}{ Landmark B' } \\
\hline \multicolumn{6}{|l|}{ 2D } \\
\hline & $\mathrm{x}$ & 0.997 & 0.992 & 0.999 & 0 \\
\hline & Y & 0.995 & 0.985 & 0.998 & 0 \\
\hline 3D & & & & & \\
\hline & $\mathrm{x}$ & 1 & 0.999 & 1 & 0 \\
\hline & Y & 0.996 & 0.988 & 0.999 & 0 \\
\hline & & & k Pog' & & \\
\hline 2D & & & & & \\
\hline & $\mathrm{x}$ & 0.998 & 0.996 & 1 & 0 \\
\hline & Y & 0.86 & 0.613 & 0.959 & 0.424 \\
\hline 3D & & & & & \\
\hline & $\mathrm{x}$ & 0.999 & 0.998 & 1 & 0 \\
\hline & Y & 0.97 & 0.918 & 0.991 & 0.001 \\
\hline & & & k NT & & \\
\hline 2D & & & & & \\
\hline & $\mathrm{x}$ & 0.995 & 0.985 & 0.998 & 0 \\
\hline & $\mathrm{Y}$ & 0.98 & 0.945 & 0.994 & 0 \\
\hline
\end{tabular}




\begin{tabular}{|c|c|c|c|c|}
\hline \multicolumn{5}{|l|}{ 3D } \\
\hline $\mathrm{x}$ & 0.999 & 0.997 & 1 & 0 \\
\hline Y & 1 & 0.999 & 1 & 0 \\
\hline \multicolumn{5}{|c|}{ Landmark Sn } \\
\hline \multicolumn{5}{|l|}{ 2D } \\
\hline$x$ & 0.987 & 0.963 & 0.996 & 0 \\
\hline Y & 0.996 & 0.99 & 0.999 & 0 \\
\hline \multicolumn{5}{|l|}{ 3D } \\
\hline $\mathrm{x}$ & 0.998 & 0.993 & 0.999 & 0 \\
\hline Y & 0.989 & 0.97 & 0.997 & 0 \\
\hline \multicolumn{5}{|c|}{ Landmark LI } \\
\hline \multicolumn{5}{|l|}{ 2D } \\
\hline $\mathrm{x}$ & 0.992 & 0.979 & 0.998 & 0 \\
\hline $\mathrm{Y}$ & 0.996 & 0.988 & 0.999 & 0 \\
\hline \multicolumn{5}{|l|}{ 3D } \\
\hline $\mathrm{x}$ & 0.998 & 0.994 & 0.999 & 0 \\
\hline $\mathrm{Y}$ & 0.995 & 0.986 & 0.999 & 0 \\
\hline \multicolumn{5}{|c|}{ Landmark LS } \\
\hline \multicolumn{5}{|l|}{ 2D } \\
\hline $\mathrm{x}$ & 0.996 & 0.988 & 0.999 & 0 \\
\hline Y & 0.998 & 0.993 & 0.999 & 0 \\
\hline \multicolumn{5}{|l|}{ 3D } \\
\hline $\mathrm{x}$ & 1 & 0.999 & 1 & 0 \\
\hline Y & 0.983 & 0.954 & 0.995 & 0 \\
\hline
\end{tabular}

${ }^{\mathrm{a}}$ ICC, Intraclass Correlation Coefficient; $\mathrm{X}$, Horizontal direction; $\mathrm{Y}$, Vertical direction; $\mathrm{P} \leq 0.05$. 